\title{
Design, fabrication and feasibility analysis of a thermo- electric wearable helmet
}

\author{
Song $\mathrm{Lv}^{\mathrm{a}}$, Wei He${ }^{\mathrm{b}, *}$, Liping Wang ${ }^{\mathrm{b}}$, Guiqiang $\mathrm{Li}^{\mathrm{a}, *}, \mathrm{Jie}^{\mathrm{J}} \mathrm{a}^{\mathrm{a}}$, Hongbing Chen ${ }^{\mathrm{c}}$, \\ Gan Zhang ${ }^{\mathrm{a}}$ \\ ${ }^{\text {a }}$ Department of thermal Science and Energy Engineering, University of Science \\ and Technology of China, Hefei, China, 230026 \\ ${ }^{\mathrm{b}}$ Department of Building Environment and Equipment, Hefei University of \\ Technology, Hefei, China, 230009 \\ ${ }^{c}$ School of Environment and Energy Engineering, Beijing University of Civil \\ Engineering and Architecture, Beijing, 100044, China \\ *Corresponding author: Tel: +86 5516290 5590; Fax: +86 55163606459 \\ E-mail: hwei@ustc.edu.cn (Dr.W. He) \\ E-mail: ligq@mail.ustc.edu.cn (Dr. G. Li).
}

\begin{abstract}
:
This paper presents a wearable thermoelectric generation system which is applied to a helmet. It involves the use of the relatively high temperature difference between the local effect of the head skin and the ambient to generate electricity for powering the LEDs. Meanwhile, the mathematical model of the thermoelectric generator (TEG) and the heat transfer process of the thermo-electric system are established and analyzed. The properties of the head underneath the helmet are also investigated and analyzed.
\end{abstract}


Furthermore, the commercially available modules have been tested and the performance of energy conversion of it has been evaluated experimentally. And the models are verified via the experiments. Models of TEG matched with LED have been certified by the experiment results are presented to optimize the number of the TEG for maximum output and the related circuits are designed. The thermo-electric wearable helmet is manufactured. In addition, the performance of the system under different environmental conditions are evaluated and predicted. The results indicate the feasibility of the wearable thermoelectric generation system and give hints for future improvement of the wearable devices using outside under different environmental conditions.

Keywords: TEG; Human body; Exercise; Wearable device; Thermoelectric

\section{Introduction}

With the high-speed development of the industrialization, the global environmental deterioration and the energy crisis are threatening the long-term steady development of mankind. Thus, governments of all countries have devoted their attentions to the research of the green environmental protection energy like the solar energy, the wind energy, the biomass energy, the geothermal energy and the ocean energy. However, the thermal energy from human body as a huge potential energy is often neglected. Compared with some other energy, the thermal energy from human body is rather 
unique for being common and stable.

Without the chemical reaction, gas emissions, and any moving parts, the thermoelectric generator (TEG) is environment-friendly and maintenance-free. Thus compared to conventional energy conversion systems, thermoelectric generators (TEG) theoretically offers a number of advantages and shows great potential in many field. [16]. In particular, parts of some applications are focused on the pursuit of energy harvesting from unused sources like mechanical vibrations and wasted heat [2, 4, 7-10]. In more details, the thermoelectric modules are commonly used to produce electricity from heat absorption restricted to aero-spatial and automotive industries, in particular, small thermoelectric generator devices used to power localized autonomous sensors [11, 12]. However, limited study focused on utilizing the thermal energy from human body for the quantity giant and without the influence by weather and geography. And with the rise of wearable devices microelectronic devices, how to provide long-term, stable and efficient power for them is a key promising technology. In 1999, Kishi et al. [13] put forward a wrist-watch with thermoelectric generators (TEGs) that used the heat released from the human body. Similarly, Leonov et al. [14] designed a wireless sensor nodes with fabricated TEGs powered by human warmth in 2007. Ziyang Wang et al. [15] made a wearable miniaturized thermoelectric generator for human body applications based on a surface micro-machined poly-SiGe thermopile. Being worn on human body, the TEG delivers an open-circuit output voltage of about $0.15 \mathrm{~V}$. Till Huesgen et al. [16] fabricated thermoelectric generators to supply Micro-ElectroMechanical system (MEMS) by harvesting thermal energy from human body. However, 
those studies applied for indoor applications and focused on the temperature difference between the human skin surface and the indoor environment. The temperature difference used by the thermoelectric generator is really low, perhaps only 4 or $5 \mathrm{~K}$ [17], the power output of thermoelectric devices is relatively low due to the performance of TEGs is significantly affected by the temperature and heat exchanger on it [18-20].

In this context, the novelty of our work is that, comparing to the previously mentioned devices and the known applications discussed above, it provide relatively large output particular by its novel structure and different application situations. It not only provides efficient method for the application of TEG on human body, but also provides a new and effective way for utilizing low thermal potential energy with low temperature. In order to make better use of the TEG without structural changes, the relatively large temperature difference is requisite for a specific TE (thermoelectric) material in view of the specific thermal environment of human body [21]. In fact, aerobic exercise could increase heat generation and loss from the human body. And the coverages on human will reduce the thermal losses to provide a relatively higher temperature by the local effect such as a headgear or helmet [22]. In addition, the human motion can also speed up the flow of the surrounding air, which can enhance the heat transfer coefficient on the cold side of TE with the ambient environment. Thus, the thermal efficiencies and the performance of the TEG will be improved greatly. Based on the ideas, the heat transfer model and the power generation model of the wearable thermoelectric generation system are established. Furthermore, the accuracy of the model is verified via a simple numerical simulation and an experiment. Then, based on 
the feasibility of the LEDs and the function of the thermoelectric generation system, the LEDs are matched with the TEG modules. What's more, the structure of the system is designed, and the wearable thermoelectric generation system is fabricated. In addition, the performance under different seasons with different outdoor temperatures and different riding speeds were evaluated and predicted, which indicated the feasibility of the wearable thermoelectric generation system.

\section{Models}

\subsection{TEG generation model}

The TEG have a specified capability of delivering electrical output power by the temperature difference between the two ends due to Seebeck effect. Typical TEG module are composed by a set of semiconductor components consisted of two different materials which mixed with two thermally conducting plates.

The basic equation for the output voltage of a thermoelectric generator is as follows [2]:

$$
V_{o c}=n \cdot\left(\alpha_{p}-\alpha_{n}\right) \cdot \Delta \mathrm{T}
$$

\subsection{The heat transfer models of the system}

The heat transfer models of the thermo-electric wearable helmet deployed on head can be discussed by the equivalent thermal circuit illustrated in Fig. 1.Typically, in case of wearable devices, the heat source is the human head, and the heat is dissipated to the ambient air outside of the devices. The hot side gains the heat from the human head and 
the cold side rejects the heat to the environment. In order to strengthen heat transfer, an aluminum thermal slug with thermal slugs was mounted on the cold side of the TE modules.

According to the Fourier's law [23], from the head to the hot side plate of the TEG, we find that

$$
Q_{\text {head }}=\frac{T_{\text {head }}-T_{h}}{R_{\text {contact } 1}}
$$

The energy that passed through the hot side of the TEG can be defined as

$$
Q_{\text {tegh }}=2 n \alpha_{\text {teg }} T_{h} I+2 n \frac{\alpha_{\text {teg }} k_{\text {teg }}}{l_{\text {teg }}}\left(T_{h}-T_{c}\right)-\frac{1}{2} I^{2} 2 n \frac{r_{\text {teg }} l_{\text {teg }}}{\mathrm{A}_{\text {teg }}}
$$

Similarly, the heat through the cold side of TEG can be expressed as

$$
Q_{\text {tegl }}=2 n \alpha_{t e g} T_{c} I+2 n \frac{\alpha_{t e g} k_{t e g}}{l_{\text {teg }}}\left(T_{h}-T_{c}\right)+\frac{1}{2} I^{2} 2 n \frac{r_{t e g} l_{t e g}}{A_{t e g}}
$$

Similarly, the energy that passed in cold side of the TEG can also be expressed as the heat flux through the thermal slug attached to the cold side of TEG.

$$
Q_{l}=\left(T_{c}-T_{\text {ambient }}\right) /\left(R_{\text {contact } 2}+R_{\text {thermal slug }}\right)
$$

In order to attain the value of $R_{\text {thermalslug }}$, we divide the heat transfers of it into two parts: heat transfer by conduction within a solid and heat transfer by convection from the boundaries of the solid to the air.

$$
\begin{gathered}
R_{\text {thermal slug }}=R_{\text {conf }}+R_{\mathrm{cov} f} \\
R_{\text {conf }}=\frac{H}{K_{\text {thermal slug }} S_{1}}
\end{gathered}
$$

In order to attain the value of $R_{\text {conf }}$ which is the thermal resistance of convection heat transfer between thermal slug and ambient air, the convection heat transfer 
coefficient $\mathrm{h}_{\text {covf }}$ must obtain [23].

$$
\begin{gathered}
C_{f x}=0.0592 \operatorname{Re}_{x}^{-1 / 5} \\
\operatorname{Re}_{x}=\frac{\rho u x}{\mu} \\
N u_{x}=\frac{h_{x} x}{k_{\text {air }}}=0.332 \operatorname{Re}_{x}^{\frac{1}{2}} \operatorname{Pr}^{\frac{1}{3}}, 0.6 \leq \operatorname{Pr} \leq 15 \\
\operatorname{Pr}=\frac{v}{\alpha}=\frac{\mu C_{p}}{k_{\text {air }}}
\end{gathered}
$$

Thus, ${ }^{S t} t_{x}$ can be obtained as below,

$$
\begin{gathered}
S t_{x}=\frac{N u_{x}}{R e_{x} \operatorname{Pr}}=\frac{h_{x}}{\rho C_{p} \mu_{\infty}}=0.332 \operatorname{Re}_{x}^{-1 / 2} \operatorname{Pr}^{-2 / 3} \\
S t_{x} \operatorname{Pr}^{2 / 3}=C_{f, x} / 2 \\
h_{x}=\frac{C_{f, x} \rho C_{p} u_{\infty}}{2 \operatorname{Pr}^{2 / 3}}
\end{gathered}
$$

And the local heat transfer coefficient $h_{x}$ is obtained,

$$
h_{x}=\frac{0.0296 x^{-1 / 5} \rho C_{p} \mu_{\infty}^{4 / 5}}{v^{-1 / 5} \cdot \operatorname{Pr}^{2 / 3}}
$$

Therefore,

$$
h_{\text {covf }}=\frac{1}{L} \int_{0}^{L} h_{x} d x
$$

After finishing calculated tablet on the air, the average heat transfer coefficient can be expressed as:

$$
h_{\mathrm{cov} f}=\frac{0.037 L^{-1 / 5} \rho \mathrm{C}_{p} u_{\infty}^{4 / 5}}{v^{-1 / 5} \cdot \operatorname{Pr}^{2 / 3}}
$$

Then the thermal resistance between the radiator and the air is:

$$
R_{\mathrm{cov} f}=\frac{1}{h_{\mathrm{cov} f} S_{2}}=\frac{v^{-1 / 5} \cdot \operatorname{Pr}^{2 / 3}}{0.037 S L^{-1 / 5} \rho C_{p} u_{\infty}^{4 / 5}}
$$


The most important typical parameters used for the models are summarized in the following table 1 . The thermal properties of air at $300 \mathrm{~K}$, atmospheric conditions are given in table 2 .

\subsection{The temperature of the head underneath a helmet}

In movement process, mechanical work done by human will cause not only the significant variation of heat production and metabolic rate, but also improves thermal heat dissipation to maintain body temperatures which is always at about $37{ }^{\circ} \mathrm{C}$. Compared with other parts of the human body, the head is not only the most demanding area of thermoregulation and thermostatic, but also the high yield zone of the heat for the whole body. Brinnel et al. [24] have made a comparison that the entire brain mass per unit of heat production is higher than that of other parts at rest. It was reported that the heat production of the head is 6 times more than other part of the body. Rasch et al. [25] has measured the heat loss from head skin at rest and during incremental exercise at $5{ }^{\circ} \mathrm{C}, 15^{\circ} \mathrm{C}, 25^{\circ} \mathrm{C}$ in 1991 . They found the heat loss from head skin and expired air decreased with increasing of the temperature, from $69 \mathrm{~W}$ and $37 \mathrm{~W}$ at $5{ }^{\circ} \mathrm{C}$ to $44 \mathrm{~W}$ and $26 \mathrm{~W}$ at $25{ }^{\circ} \mathrm{C}$ at rest. At a work load of $150 \mathrm{~W}$ the heat loss tended to increase with increasing of the temperature, from $119 \mathrm{~W}$ at $5{ }^{\circ} \mathrm{C}$ to $132 \mathrm{~W}$ at $25^{\circ} \mathrm{C}$. When exercising in the heat in forced convection, heat loss from the head was estimated at $200 \mathrm{~W}$ to 250

W. There are several studies [24-26] reported that a considerable amount of heat can be lost from the head in spite the fact that the area of the head only one ninth of the whole body. Heat transfer properties and temperature distribution of helmets have been widely investigated using human experimental measurements or thermal manikin heads .The bicycle helmets, the motorcycle helmets, the safety helmets, the cricket helmets, the full face helmets, the open face helmet, the aerodynamic helmet have been studied. 
These $[27,28]$ studies indicate that helmets have a negative impact on air circulation over the head and helmet only affect the local skin temperature and sweat rate. They reported the temperatures underneath helmet range from 30.5 to $36.5^{\circ} \mathrm{C}$. The variation seems mainly due to differences of the structures and the airflow over the skin under the helmet.

Nowadays, helmet manufacturers put the design of the bicycle helmet a trend towards more open structures of their new designs [29]. In order to get better use of the thermal energy of the human body, this study mainly refers to the traditional open face helmet. Thus, in the following discussion, the highest temperature is $36.5^{\circ} \mathrm{C}$.

\section{Experimental verification}

For our research, the most suitable couple of materials available on the market, considering the reasonable price, a small fraction of a temperature difference of human body and ambient, and a relatively high conversion efficiency, is bismuth telluride (BiTe) compounds. The commercial BiTe modules used in the experiment are fabricated by ShenMing Yang Electronics Ltd. (product code: TEG1-241-1.4-1.2). The size of the TEG is $55 \times 55 \times 3.4 \mathrm{~mm}^{3}$.There are 241 couples in the module. The experimental TE power generator test system have been established as follows.

As is shown in Fig. 2, in order to enhance the heat dissipation, a heat sink with thermal slugs was mounted on the cold side of each TE module. There is a heater providing constant heat fluxes for three TEG modules. The electric heater provided by Shanghai Songdao heating sensor Co Ltd is chosen to supply heat energy to the hot side of three TEG modules. It can provide constant $100 \mathrm{~W} / \mathrm{m}^{2}$ heat fluxes for three TEG 
modules. Some thermocouples were attached to the different parts of the modules to measure its temperatures. The multimeters and data logger have been used to measure and record the relevant data. The uncertainty of the thermocouples, the ammeter and the volt-meter are listed in the Table 3.

The system was tested in steady state and dynamic conditions using steps of the electric heat power and a rheostat as the load of the TE modules. We get the electrical characteristics of the TE modules by change the resistance at different values in the range 0 to $30 \Omega$. The output power is shown in Fig. 3. The temperature difference between the hot side and cold side of the TE module is about $10{ }^{\circ} \mathrm{C}$.

A MATLAB code has been written. We provided the TEG model an internal resistance of $5.15 \Omega$ and an open-circuit voltage of $2 \mathrm{~V}$ and the same heat fluxes with the experiment, respectively for comparison. The experimental results and simulation results are also presented in Fig. 3. The comparison between the experimental results and that of the model permits to validate the experimental procedure. The thermal properties of air at $300 \mathrm{~K}$, experimental conditions are summarized in Table 2.

The results indicate that the internal resistance of the three TEG modules in series is $15.45 \Omega$. Thus, the average resistance of each is $5.15 \Omega$. The maximum open circuit voltage of three pieces of TEG power generation sheet series is $2.01 \mathrm{~V}$, and the maximum output is $0.0397 \mathrm{~W}$ when the external resistance value of $15.45 \Omega$ (excluding line losses). The power generation efficiency of the TEG is $0.48 \%$.

The variation of the voltage and output power characteristics for an electric load of $15 \Omega$ of the TE module as a function of the temperature difference between the hot 
side and cold side of the TE module is shown in Fig. 4.

The results of the experiment and numerical simulation are consistent. The comparison between the experimental results and that of the model permit to validate the accuracy of model.

\section{Helmet Design and Fabrication}

\subsection{Matching with the LEDs}

It is difficult to use the relatively small power produced by the TEGs to powering the conventional light, but high brightness low power LEDs provide a good choice for taking advantage of the power. In our experiments and prototype, the LEDs provided by Zhujiang Electronic Industry Co Ltd is chosen as the light emitting unit. The supply voltage is $2.0 \mathrm{~V}$ and the forward current is $5 \mathrm{~mA}$.

Maximum power output of a thermoelectric module is defined as the power output generated when the module resistance matches the load resistance. As explained in [14], knowing the internal resistance makes it easy to determine the maximum output power $p_{\max }$ using

$$
p_{\max }=\frac{V_{o}^{2}}{4 R_{\text {int }}\left(1+\frac{R_{\text {int }}}{R_{L}}\right)^{2}}
$$

For stable and normal work, The TE modules is required to have a wide range of operating voltage up to $4 \mathrm{~V}$ while it can supply a stable current level of $5 \mathrm{~mA}$ for the LED. The luminance signal cannot be guaranteed as the requirements due to the small range of a single LED light emission. Considering the structure and design requirements 
of the helmet,we chooses 16 high-brightness LEDs and divided them into two groups, and put them in the back of the helmet to indicate steering. Thus, 6 TE modules are needed to supply the LEDs. In order to provide the output of TEG to match the LEDs, the two groups of LEDs must be connected in parallel. The simple circuit design according to Ohm's Law, which is shown in Fig. 5.

A current limiting resistor or a capacitor is placed at the middle of line to deliver precision overvoltage protection and overcurrent protection due to the limitation of the TEG's output. The 6 TE modules in series connection can provide the maximum output power of $0.0794 \mathrm{~W}$ and an open-circuit output voltage of about $4.02 \mathrm{~V}$ on a matched external load when the outdoor temperature is $11.5^{\circ} \mathrm{C}$ and no wind.

\subsection{Helmet Fabrication}

According to the discussion, 6 TEG modules is already satisfied with the requirement of LEDs on the helmet. The main effect of helmet is for security, because of this kind of particularity, a large thermal material and a certain thickness of the low density foam were usually used to the lining materials. Based on the shape of the human head, 6 TEG modules discussed above is evenly installed on the top of the helmet.

The hot end was put inside the helmet makes it in close contact with the top of the scalp. The cold end and the thermal slug are exposed to the air. The two group of the LEDs are distributed in the back of the helmet on both sides, and are arranged into two arrow shape. Electronic components are connected according to the circuit diagram and arranged in the helmet on both sides of the medial. The design of the helmet is shown 
in Fig. 6. Thus, besides the protections of the head in traffic accidents, the thermoelectric wearable helmet could improve security of riding a bicycle by adding the indicator lights.

The new type of bicycle helmet has been developed in our laboratory and the prototypes have been built. It was developed by a commercial helmet as shown in Fig. 7.(a) The results of wearing the helmet for 0.5 hour ride under the specified climates (the ambient temperature is $13{ }^{\circ} \mathrm{C}$ and the wind speed is $2 \mathrm{~m} / \mathrm{s}$ ) is shown in Fig. 7. (b) When the switch is closed, the LEDs of both sides all lit up.

\section{Discussion}

In this paper a thermo-electric wearable helmet was proposed. The system was tested under experimental condition, and it worked normally. However, with the change of environmental conditions (like temperature, wind speed and so on) [30], the ability of TE modules on the helmet using the heat of head to produce electricity can also make tremendous change. In order to further discuss the output performance of the device under different environmental conditions, series of predictions are made. Taking Hefei China as an example, the basic meteorological data from Hefei Municipal Meteorological Bureau is shown in Table 4.

\subsection{The effect of ambient temperature}

From the measured open-circuit voltage a device output power of $0.0397 \mathrm{~W}$. This value is one order of barely lower than the simulated value of $0.04 \mathrm{~W}$. The major source 
for this deviation is the data acquisition unit of the experiment due to problems in low measuring precision which are listed in Table 3. Therefore, the simulation results fitted well with experiment values.

The certified model is used to simulate the output performance of the thermoelectric wearable helmet under the specified conditions (the ambient temperature is 13 ${ }^{\circ} \mathrm{C}$ and the wind speed is $2 \mathrm{~m} / \mathrm{s}$ ). The other parameters are the same as those in the experiment and simulation above. We take the temperature change in Hefei as an example, the output characteristics of the thermo-electric wearable helmet as a function of the ambient temperature are shown in Fig. 8. Thus, we can verify that the voltage is proportional to $\Delta T$, and the power to $\Delta T^{2}$. At the same time, the variation of the output changed with the temperature difference between the head and the ambient can be extrapolated. It can be seen from Fig. 9, when the ambient temperature is lower than $12{ }^{\circ} \mathrm{C}$, the TE modules produced enough electricity to power the entire system and some to spare, which also presents thethermo-electric device above with 6 designed TE modules functionality implemented and run well by powered by human body's heat. The maximum output power up to $8.32 \mathrm{~W}$ in local meteorological conditions. In Hefei, China, there are the average minimum temperature of 6 months which is able to meet the requirement. The extreme minimum temperature of 9 months except June, July and August are all meet the requirements. The system runs normally only powered by the TEGs. In addition to other time of the year when the temperature is higher than the design value, two more TE modules are needed for the wearable thermoelectric generation system to run well. 


\subsection{The effect of riding speed}

The variation of the output characteristics as a function of cycling speed is shown in Fig. 9 Fig. 11. They represent three different seasons and different ambient temperature, respectively. Riding in the wild is the complex real condition to air turbulence, we assume that there is no natural wind and the forced convection is generated by the relative motion of cycling. It can be seen from results that with the increase of the cycling speed, the electrical efficiencies and the output performance of the TE module can all be improved.

When cycling in the experimental conditions of ambient temperature $11.5^{\circ} \mathrm{C}$ at the average velocity of $20 \mathrm{Km} / \mathrm{h}$, Fig. 9 reveal that the open-circuit output voltage is 5.37 V. Moreover, the output power delivered on a matched external load amounts to $0.9324 \mathrm{~W}$. Thus, less than 5 TE modules are need to supply the LEDs. Similarly, as is shown in Fig. 10, when cycling in the coldest months of the year, there are a substantial increase of the open-circuit output voltage and the output power. Being worn on head, the TEG delivers an output voltage of around $9.38 \mathrm{~V}$ when cycling at $20 \mathrm{Km} / \mathrm{h}$. Connected to a matched external load, it is estimated to produce an output power of about $2.85 \mathrm{~W}$.

However, when the design apply to the hottest month of the summer, analysis of the thermoelectric generator in Fig. 11 shows that the wearable thermoelectric generation system using heat of head is not feasible for the hot weather. We could improve it by increasing the number of the TE modules or adding an electricity storage device for power shifting at temperature changes. 


\section{Conclusion}

This work describes a part of fabrication and feasibility analysis of a thermoelectric wearable helmet. The mathematical model of the thermo-electric system was built, and the simulation and experiment was compared. A particular attention must be paid to the design of the heat exchangers. Models of TEG matched with LED have been certified by the experiment results are presented to optimize the number of the TEG for maximum output. In addition, the performance of the thermo-electric system was analyzed based on the ambient temperatures, different cycling (wind) speeds. Our study shows that the use of TE modules can be a very convenient way. The produced electricity will run the LEDs to increase the conspicuity of the vehicle. This will decrease the polluting batteries and eliminate the human thermal discomfort by long time to wear a helmet.

Furthermore, the results proved that thermoelectric modules which appears to be commercial unfeasible, owing to the significantly higher cost and low energy conversion efficiency, also exhibit a promising performance for electrical power generation using waste heat in the temperature range $250-320 \mathrm{~K}$. The results reported in this paper show that the temperature which is consistent with the body temperature can readily be obtained using commercially available modules with an appropriate design and produce the electricity range from $\mathrm{mW}$ to $\mathrm{W}$.

\section{Acknowledgment}

The study was sponsored by the Twelfth Five-year Science and Technology Support Key Project of China (No. 2012BAJ08B04), the Fundamental Research Funds 
for the Central Universities (WK6030000011), the National Science Foundation of China (Grant No. 51408578), Anhui Provincial Natural Science Foundation (1508085QE96), DongGuan Innovative Research Team Program (No. 2014607101 008), the Fundamental Research Funds for the Central Universities, and China Postdoctoral Science Foundation (2014M550350, 2015T80665).

\begin{tabular}{|c|c|c|c|}
\hline \multicolumn{4}{|c|}{ Nomenclature } \\
\hline $\mathrm{A}_{t e g}$ & rea of TEG, $\mathrm{m}^{2}$ & $R_{\text {conf }}$ & $\begin{array}{l}\text { resistance of the heat conduction in } \\
\text { thermal slug, K/W }\end{array}$ \\
\hline$C_{f x}$ & local friction coefficient & $R_{\operatorname{cov} f}$ & $\begin{array}{l}\text { thermal resistance of convection } \\
\text { heat transfer between thermal slug } \\
\text { and ambient air, K/W }\end{array}$ \\
\hline$C_{p}$ & specific heat, $\mathrm{kJ} /(\mathrm{kg} \cdot \mathrm{K})$ & $\operatorname{Re}$ & Reynolds number \\
\hline$h_{\text {covf }}$ & $\begin{array}{l}\text { coefficient of convection heat } \\
\text { transfer of the thermal slug, } \\
\mathrm{W} /\left(\mathrm{m}^{2} \cdot \mathrm{K}\right)\end{array}$ & $r_{\text {teg }}$ & electrical resistivity of TEG, $\Omega \cdot \mathrm{m}$ \\
\hline$h_{x}$ & $\begin{array}{l}\text { heat transfer coefficient along the } \\
\text { length of the thermal slug at the } \\
\text { location of a convective, } \mathrm{W} /\left(\mathrm{m}^{2} \cdot \mathrm{K}\right)\end{array}$ & $R_{\text {int }}$ & $\begin{array}{l}\text { the internal resistance of the power } \\
\text { supply, } \Omega\end{array}$ \\
\hline$H$ & the height of the thermal slug, $\mathrm{m}$ & $R_{L}$ & resistance of LED, $\Omega$ \\
\hline$I$ & current, $\mathrm{A}$ & $S_{1}$ & $\begin{array}{l}\text { the cross section area of the heat } \\
\text { sink, } \mathrm{m}^{2}\end{array}$ \\
\hline $\mathrm{k}_{\text {teg }}$ & $\begin{array}{l}\text { thermal conductivity of TEG, } \\
\mathrm{W} /(\mathrm{m} \cdot \mathrm{K})\end{array}$ & $S_{2}$ & the total area of the thermal slug, $\mathrm{m}^{2}$ \\
\hline$K_{\text {thermal slug }}$ & $\begin{array}{l}\text { thermal conductivity of the thermal } \\
\text { slug, } \mathrm{W}(\mathrm{m} \cdot \mathrm{K})\end{array}$ & $S t$ & Stanton number \\
\hline$k_{\text {air }}$ & $\begin{array}{l}\text { thermal conductivity of air, } \\
\mathrm{W}(\mathrm{m} \cdot \mathrm{K})\end{array}$ & $T_{\text {head }}$ & the head temperature of the skin, $\mathrm{K}$ \\
\hline$l_{\text {teg }}$ & the length of TEG, $m$ & $\mathrm{~T}_{\mathrm{h}}$ & hot side temperature of TEG, $\mathrm{K}$ \\
\hline $\mathrm{L}$ & the length of the thermal slug, $\mathrm{m}$ & $\mathrm{T}_{\mathrm{c}}$ & cold side temperature of TEG, $\mathrm{K}$ \\
\hline
\end{tabular}




\begin{tabular}{|c|c|c|c|}
\hline$n$ & number of thermocouples & $T_{\text {ambient }}$ & temperature of ambient air, $\mathrm{K}$ \\
\hline $\mathrm{Nu}$ & Nuselt number & $u$ & wind speed, $\mathrm{m} / \mathrm{s}$ \\
\hline $\operatorname{Pr}$ & Prandtl number & $V_{o c}$ & open circuit voltage, $\mathrm{V}$ \\
\hline $\mathrm{p}$ & the output power, W & $\alpha_{n}$ & $\begin{array}{l}\text { Seebeck coefficients for n-type } \\
\text { material, V/K }\end{array}$ \\
\hline$p_{\max }$ & the maximum output power, $\mathrm{W}$ & $\alpha_{p}$ & $\begin{array}{l}\text { Seebeck coefficients for } \mathrm{p} \text {-type } \\
\text { material, } \mathrm{V} / \mathrm{K}\end{array}$ \\
\hline$Q_{\text {head }}$ & energy that loss from the head, $\mathrm{J}$ & $\alpha_{t e g}$ & Seebeck coefficient for TEG, V/K \\
\hline$Q_{\text {tegh }}$ & $\begin{array}{l}\text { energy that passed in hot side of the } \\
\text { TEG, J }\end{array}$ & $\rho$ & density of air, $\mathrm{kg} / \mathrm{m}^{3}$ \\
\hline$Q_{\text {tegl }}$ & $\begin{array}{l}\text { energy that passed in cold side of } \\
\text { the TEG, } \mathrm{J}\end{array}$ & $\mu$ & kinematic viscosity, $\mathrm{m}^{2} / \mathrm{s}$ \\
\hline$R_{\text {contact } 1}$ & $\begin{array}{l}\text { thermal contact resistance between } \\
\text { TEG and head skin, K/W }\end{array}$ & $\alpha$ & thermal diffusivity, $\mathrm{m}^{2} / \mathrm{s}$ \\
\hline$R_{\text {contact } 2}$ & $\begin{array}{l}\text { thermal contact resistance between } \\
\text { TEG and thermal slug, K/W }\end{array}$ & $v$ & dynamic viscosity, $\mathrm{N} \cdot \mathrm{s} / \mathrm{m}^{2}$ \\
\hline$R_{\text {thermal slug }}$ & $\begin{array}{l}\text { thermal resistance of the thermal } \\
\text { slug, K/W }\end{array}$ & $\Delta \mathrm{T}$ & $\begin{array}{l}\text { temperature difference between the } \\
\text { thermocouple, } \mathrm{K}\end{array}$ \\
\hline
\end{tabular}




\section{References}

[1] D.M. Rowe, Thermoelectrics, an environmentally-friendly source of electrical power, Renewable energy, 16 (1999) 1251-1256.

[2] D.M. Rowe, CRC handbook of thermoelectrics, CRC press, 1995.

[3] D. Rowe, G. Min, Evaluation of thermoelectric modules for power generation, Journal of Power Sources, 73 (1998) 193-198.

[4] R. Nuwayhid, D. Rowe, G. Min, Low cost stove-top thermoelectric generator for regions with unreliable electricity supply, Renewable energy, 28 (2003) 205-222.

[5] T. Wang, W. Luan, W. Wang, S.-T. Tu, Waste heat recovery through plate heat exchanger based thermoelectric generator system, Applied Energy, 136 (2014) 860-865. [6] S.B. Riffat, X. Ma, Thermoelectrics: a review of present and potential applications, Applied thermal engineering, 23 (2003) 913-935.

[7] D. Champier, J. Bedecarrats, M. Rivaletto, F. Strub, Thermoelectric power generation from biomass cook stoves, Energy, 35 (2010) 935-942.

[8] D. Dai, Y. Zhou, J. Liu, Liquid metal based thermoelectric generation system for waste heat recovery, Renewable energy, 36 (2011) 3530-3536.

[9] H.-K. Ma, C.-P. Lin, H.-P. Wu, C.-H. Peng, C.-C. Hsu, Waste heat recovery using a thermoelectric power generation system in a biomass gasifier, Applied thermal engineering, 88 (2015) 274-279.

[10] H. Gao, G. Huang, H. Li, Z. Qu, Y. Zhang, Development of stove-powered thermoelectric generators: A review, Applied thermal engineering, 96 (2016) 297-310. [11] R. Bonin, D. Boero, M. Chiaberge, A. Tonoli, Design and characterization of small thermoelectric generators for environmental monitoring devices, Energy Conversion and Management, 73 (2013) 340-349.

[12] M. Jaworski, M. Bednarczyk, M. Czachor, Experimental investigation of thermoelectric generator (TEG) with PCM module, Applied thermal engineering, 96 (2016) 527-533.

[13] M. Kishi, H. Nemoto, T. Hamao, M. Yamamoto, S. Sudou, M. Mandai, S. Yamamoto, Micro thermoelectric modules and their application to wristwatches as an energy source, in: Thermoelectrics, 1999. Eighteenth International Conference on, IEEE, 1999, pp. 301-307. 
[14] V. Leonov, T. Torfs, P. Fiorini, C. Van Hoof, Thermoelectric converters of human warmth for self-powered wireless sensor nodes, Sensors Journal, IEEE, 7 (2007) 650657.

[15] Z. Wang, V. Leonov, P. Fiorini, C. Van Hoof, Realization of a wearable miniaturized thermoelectric generator for human body applications, Sensors and Actuators A: Physical, 156 (2009) 95-102.

[16] T. Huesgen, P. Woias, N. Kockmann, Design and fabrication of MEMS thermoelectric generators with high temperature efficiency, Sensors and Actuators A: Physical, 145 (2008) 423-429.

[17] J. Weber, K. Potje-Kamloth, F. Haase, P. Detemple, F. Völklein, T. Doll, Coinsize coiled-up polymer foil thermoelectric power generator for wearable electronics, Sensors and Actuators A: Physical, 132 (2006) 325-330.

[18] R. Nuwayhid, R. Hamade, Design and testing of a locally made loop-type thermosyphonic heat sink for stove-top thermoelectric generators, Renewable energy, 30 (2005) 1101-1116.

[19] P.M. Attia, M.R. Lewis, C.C. Bomberger, A.K. Prasad, J.M. Zide, Experimental studies of thermoelectric power generation in dynamic temperature environments, Energy, 60 (2013) 453-456.

[20] N. Wojtas, L. Rüthemann, W. Glatz, C. Hierold, Optimized thermal coupling of micro thermoelectric generators for improved output performance, Renewable energy, 60 (2013) 746-753.

[21] V. Leonov, R.J. Vullers, Wearable electronics self-powered by using human body heat: The state of the art and the perspective, Journal of Renewable and Sustainable Energy, 1 (2009) 062701

[22] C.P. Bogerd, J.-M. Aerts, S. Annaheim, P. Bröde, G. De Bruyne, A.D. Flouris, K. Kuklane, T.S. Mayor, R.M. Rossi, A review on ergonomics of headgear: Thermal effects, International Journal of Industrial Ergonomics, 45 (2015) 1-12.

[23] T.L. Bergman, F.P. Incropera, A.S. Lavine, Fundamentals of heat and mass transfer, John Wiley \& Sons, 2011.

[24] H. Brinnel, M. Cabanac, Tympanic temperature is a core temperature in humans, Journal of Thermal Biology, 14 (1989) 47-53.

[25] W. Rasch, P. Samson, J. Cote, M. Cabanac, Heat loss from the human head during exercise, Journal of Applied Physiology, 71 (1991) 590-595. 
[26] G. Wimer, Wearing a cap, thermoregulation, and thermal sensation during running in a hot environment, Journal of Sports Medicine and Physical Fitness, 49 (2009) 272. [27] A. Van Brecht, D. Nuyttens, J.-M. Aerts, S. Quanten, G. De Bruyne, D. Berckmans, Quantification of ventilation characteristics of a helmet, Applied ergonomics, 39 (2008) 332-341.

[28] G. De Bruyne, J.-M. Aerts, J. Vander Sloten, J. Goffin, I. Verpoest, D. Berckmans, Quantification of local ventilation efficiency under bicycle helmets, International Journal of Industrial Ergonomics, 42 (2012) 278-286.

[29] J.F. Lee, S.R. Brown, A.P. Lange, R.M. Brothers, Effect of an Aerodynamic Helmet on Head Temperature, Core Temperature, and Cycling Power Compared With a Traditional Helmet, The Journal of Strength \& Conditioning Research, 27 (2013) 3402-3411.

[30] F.S. Moraes, L.C. Santos, R.N. Alencar, É.V. Sempels, F.J. Lesage, Solar thermoelectric generator performance relative to air speed, Energy Conversion and Management, 99 (2015) 326-333.

\section{Figures}

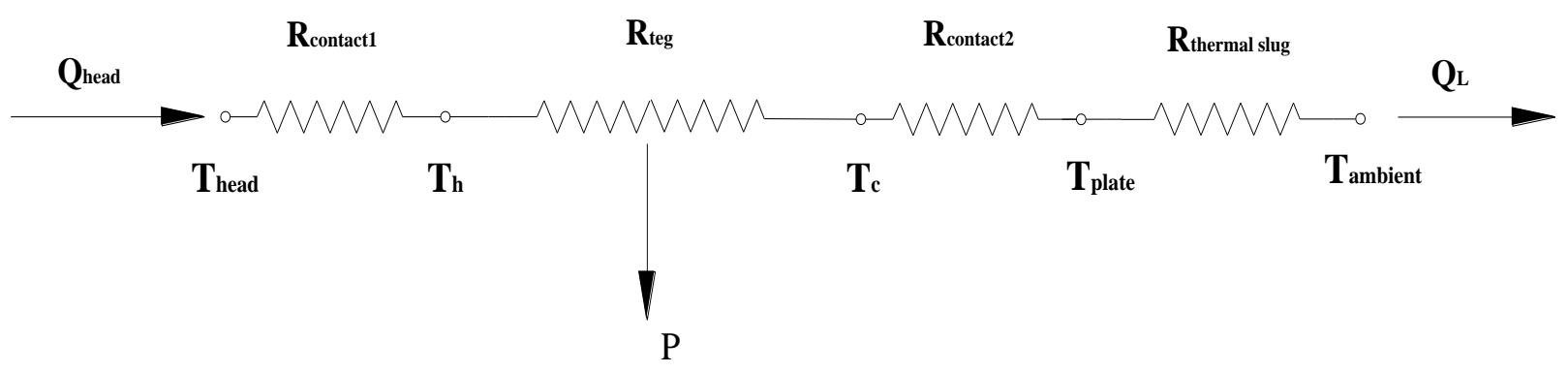

Fig. 1. Equivalent circuit model of the system deployed on head 


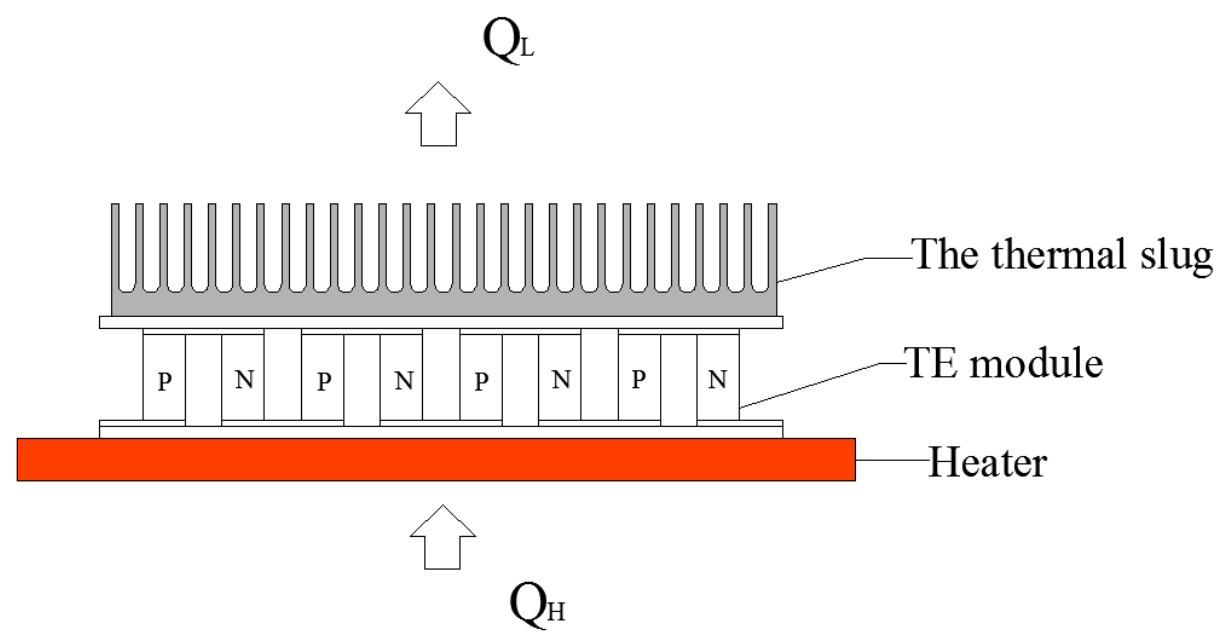

Fig. 2. Experimental TE power generator test system.

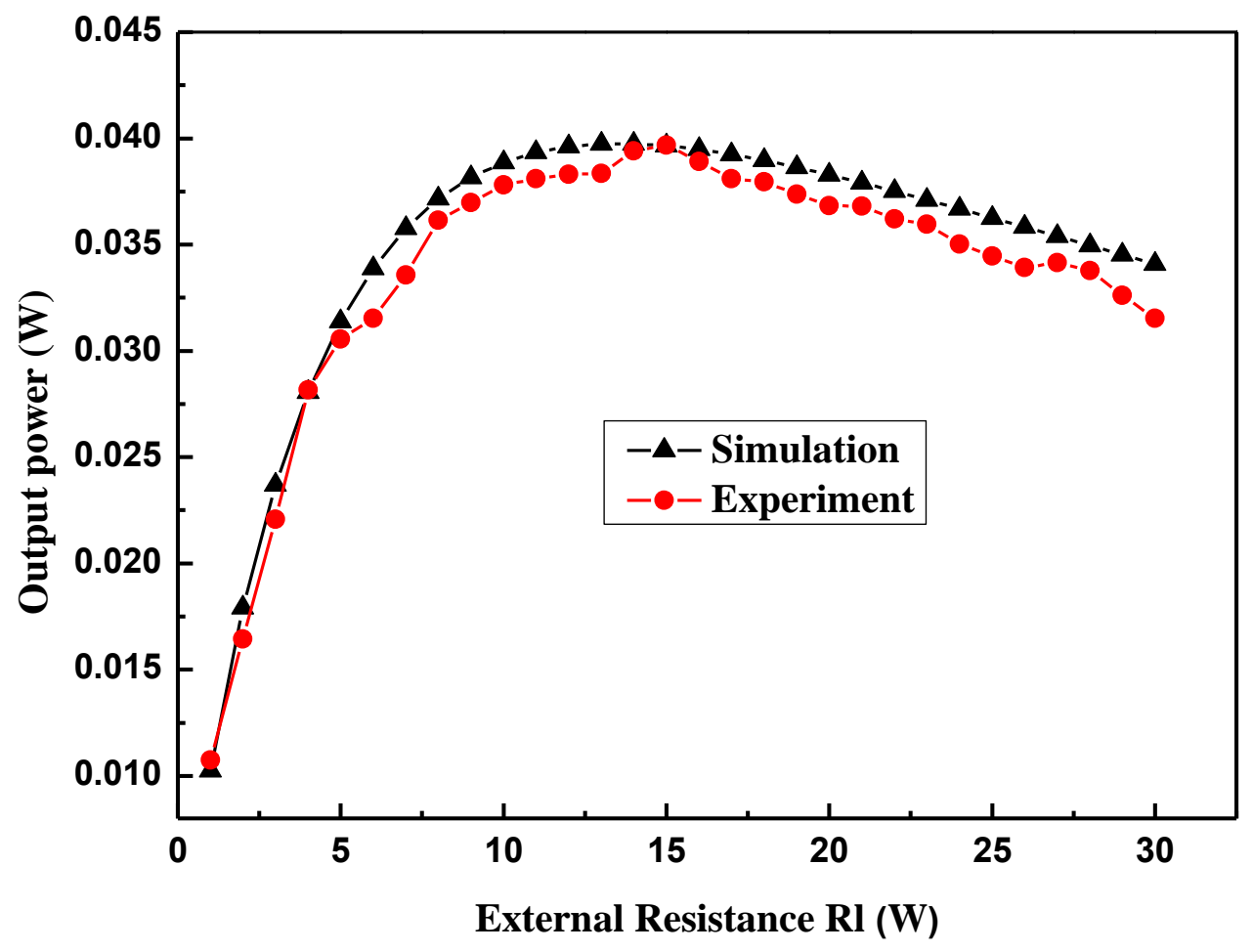

Fig. 3. Change in output power with an external load 


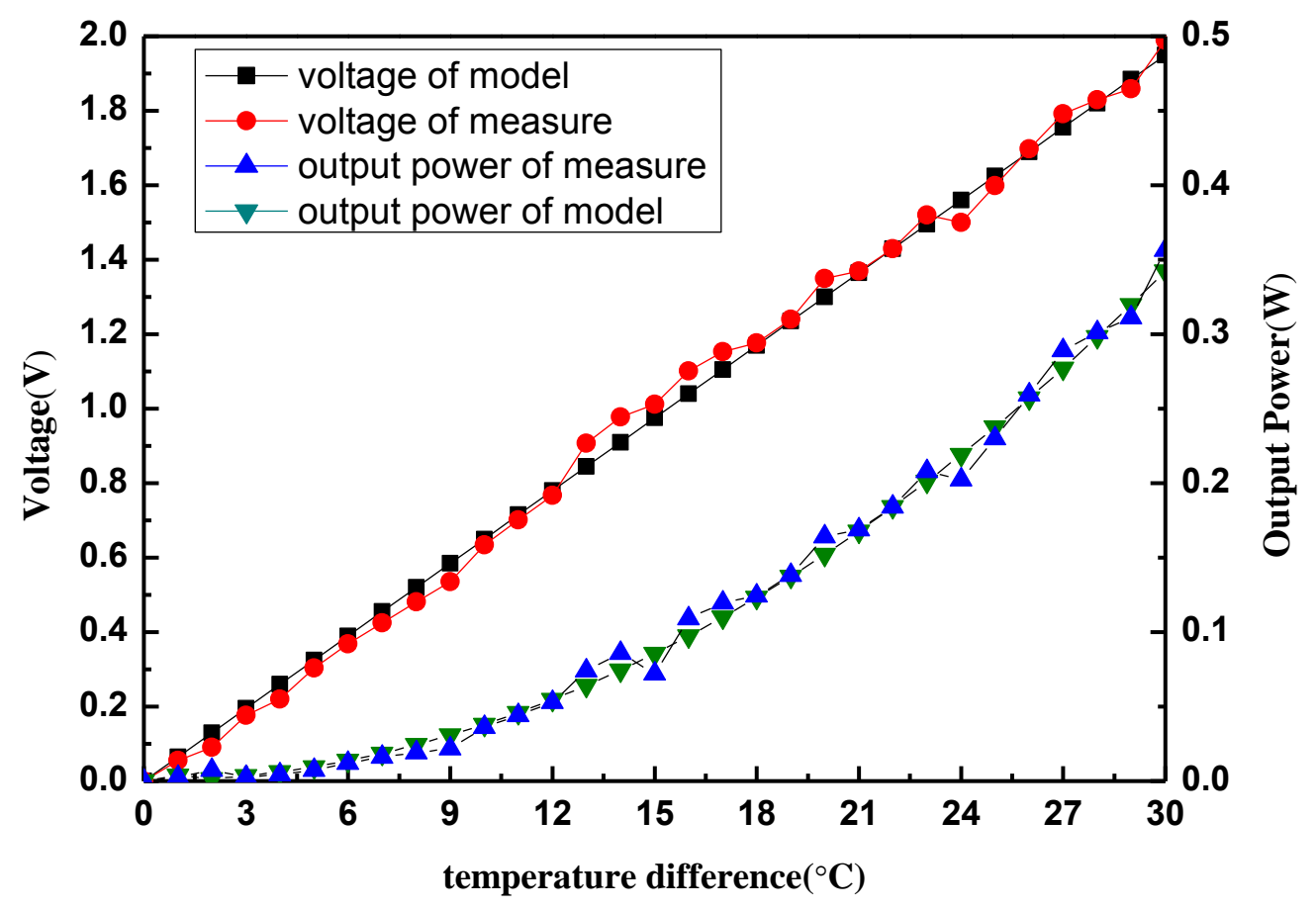

Fig. 4. Voltage and output power function of temperature difference

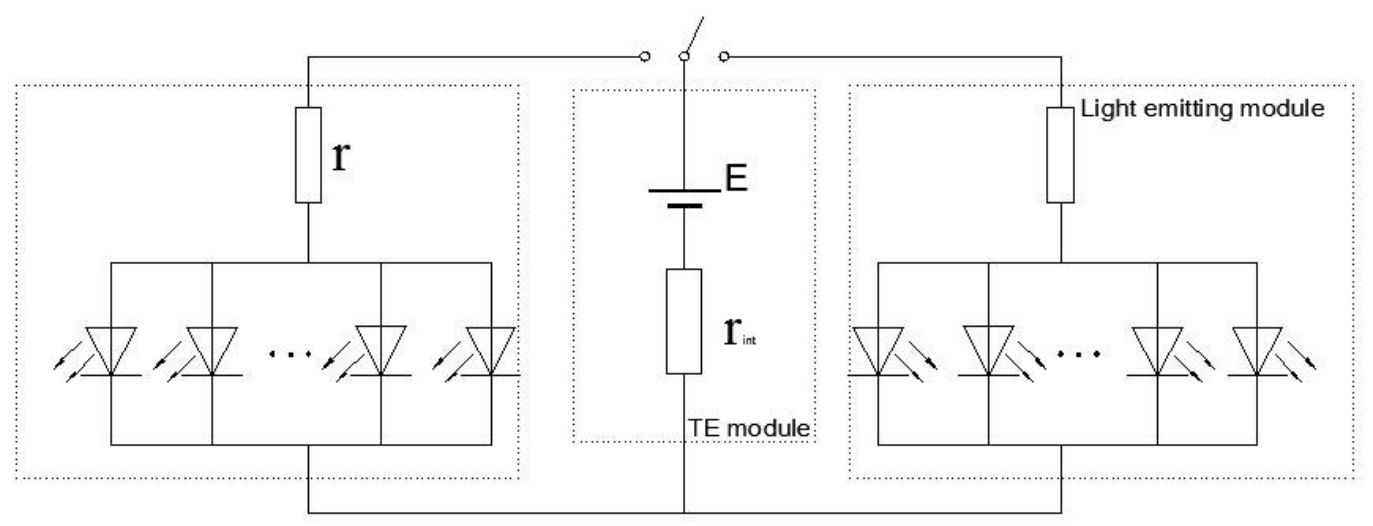

Fig. 5. Schematic of the LEDs Circuit 

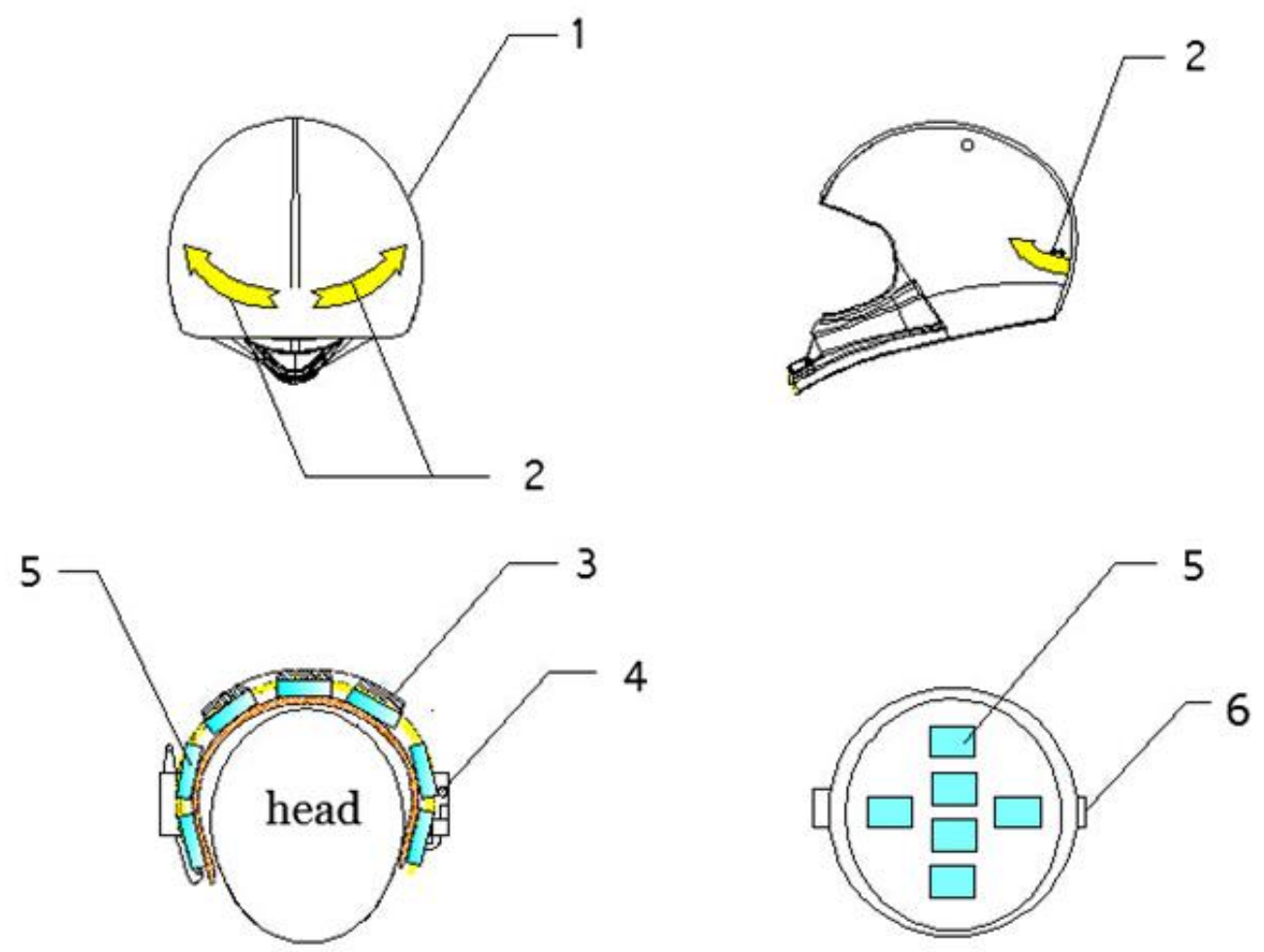

1. Helmet; 2. LED light indicator group; 3. Cooling fins; 4. Left and right turn switch; 5 . Thermoelectric power generation chip set; 6 . Indicator power supply circuit;

Fig. 6. The design of the helmet.
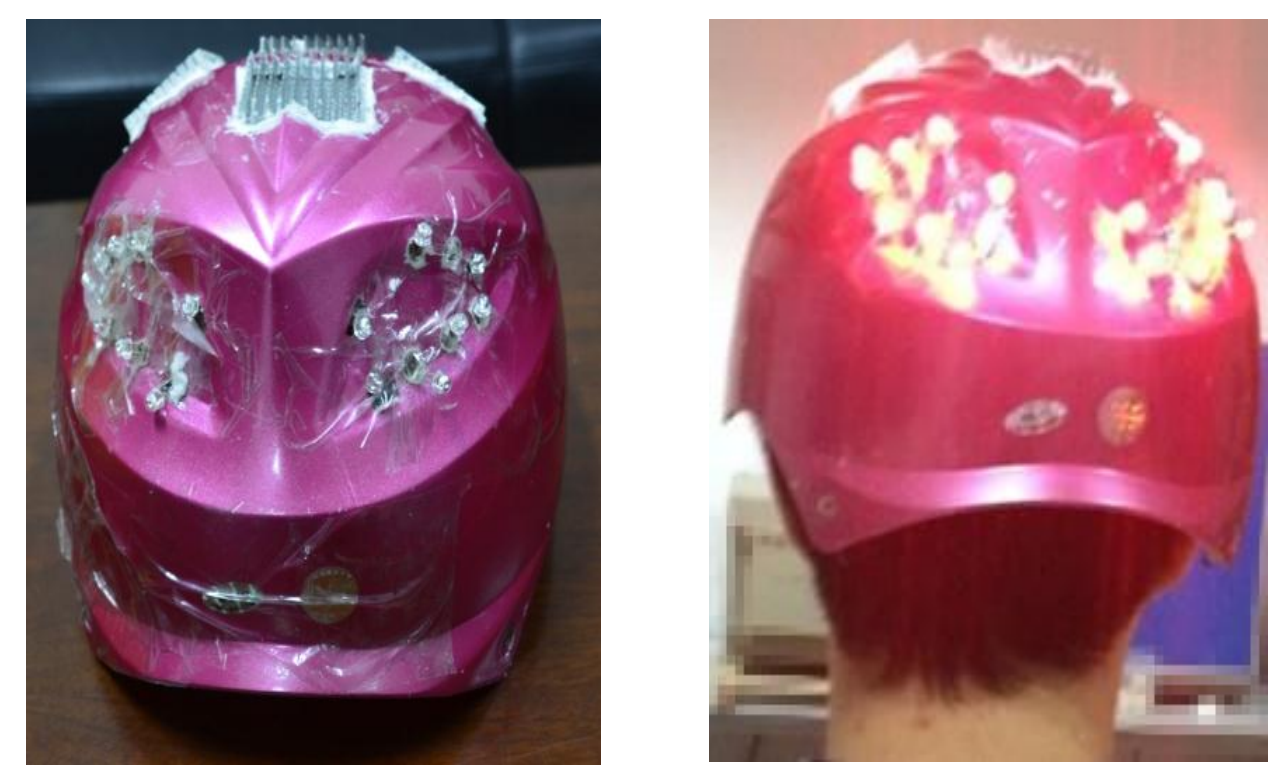

Fig. 7. (a) The prototypes of the helmet, (b) The result of the experiment. 


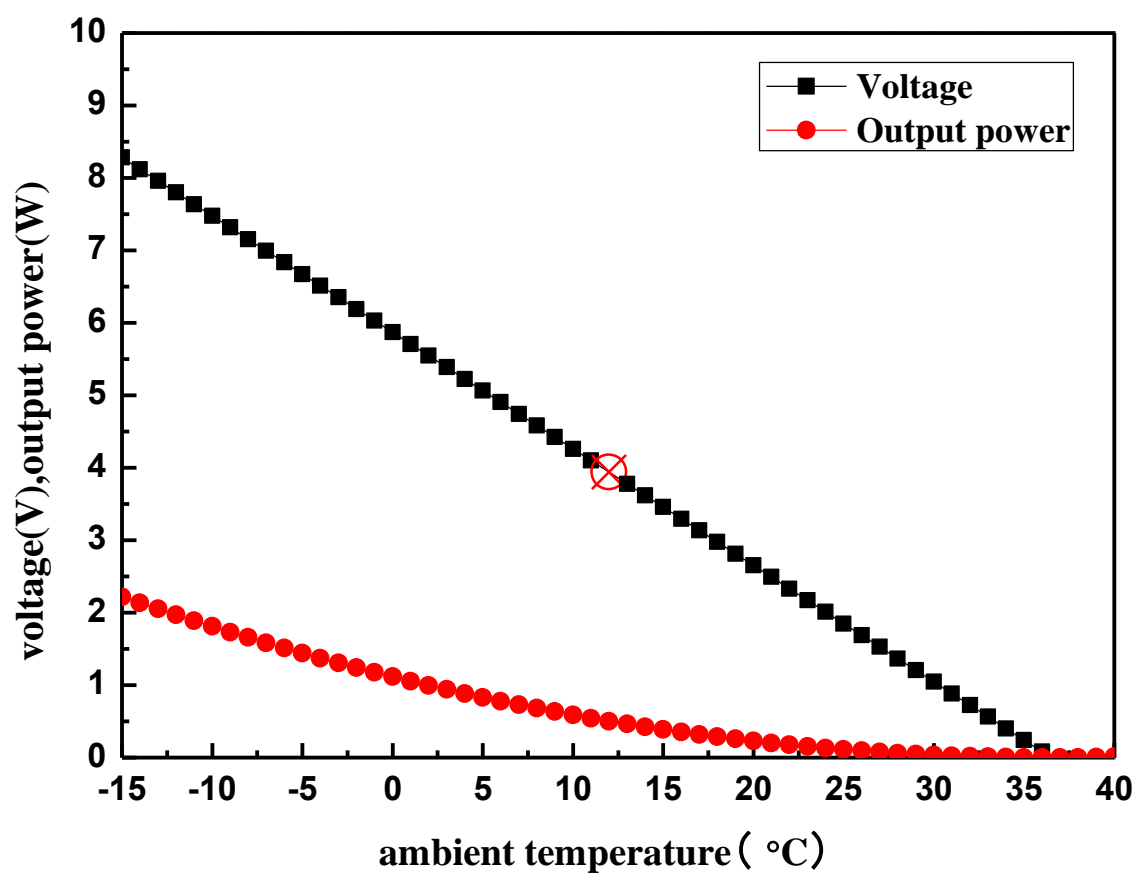

Fig. 8. Voltage and output power function of ambient temperature.

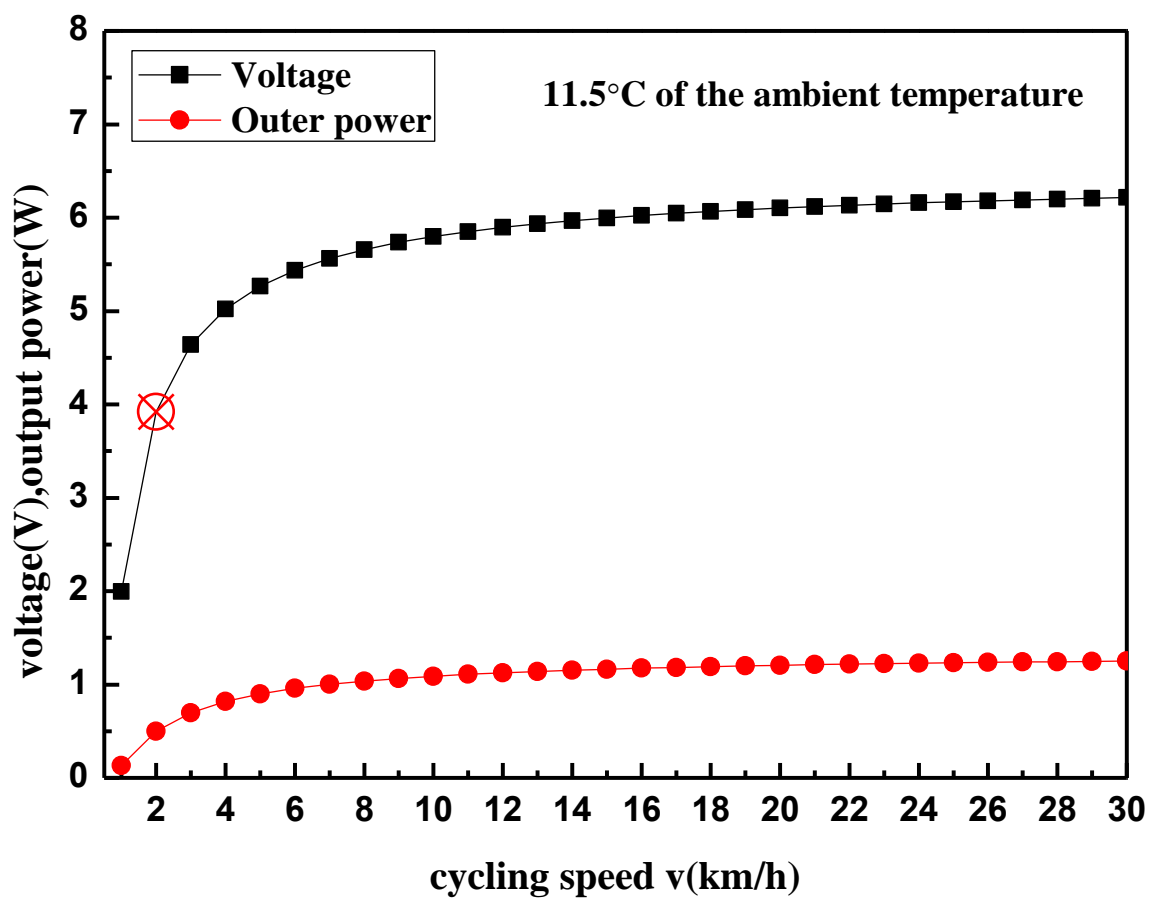

Fig. 9. Voltage and output power function of cycling speed under the experimental conditions of ambient temperature of $11.5^{\circ} \mathrm{C}$. 


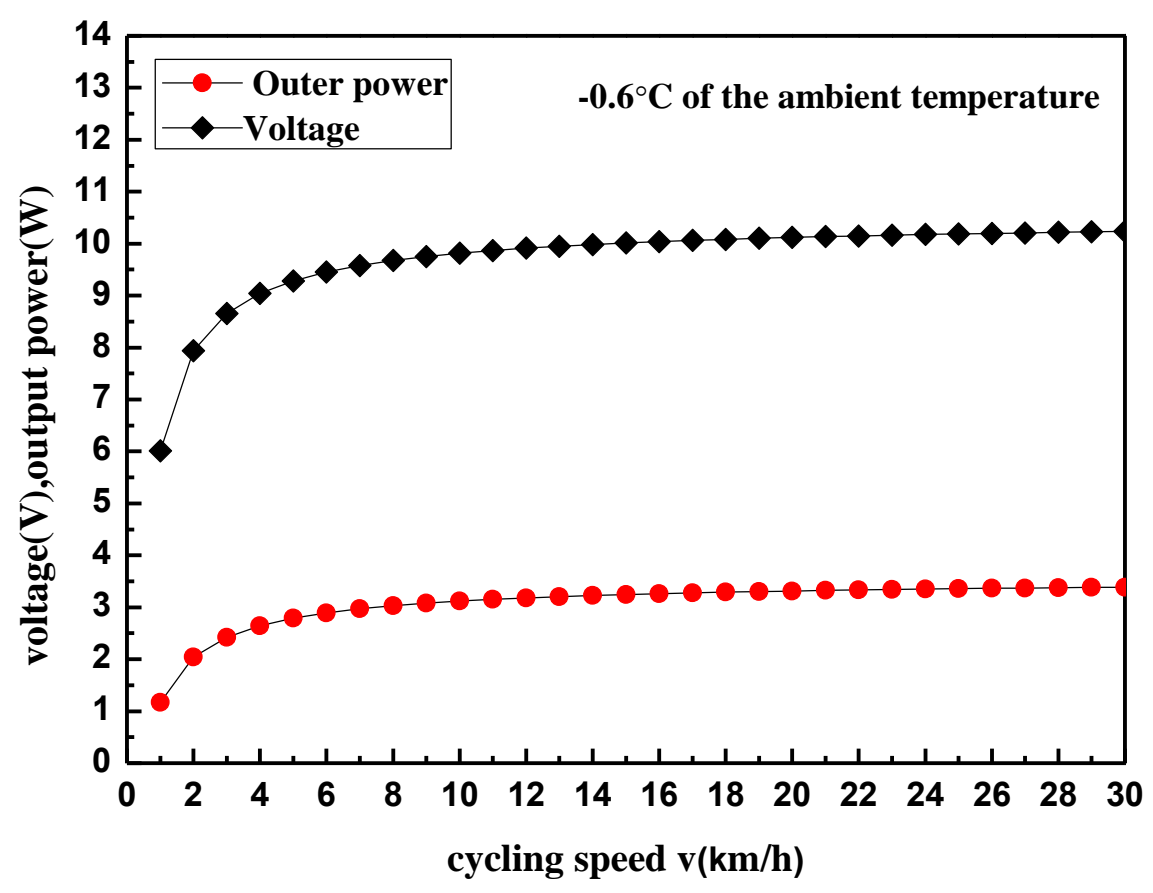

Fig. 10. Voltage and output power function of cycling speed at the lowest average temperature of the year temperature of $-0.6^{\circ} \mathrm{C}$.

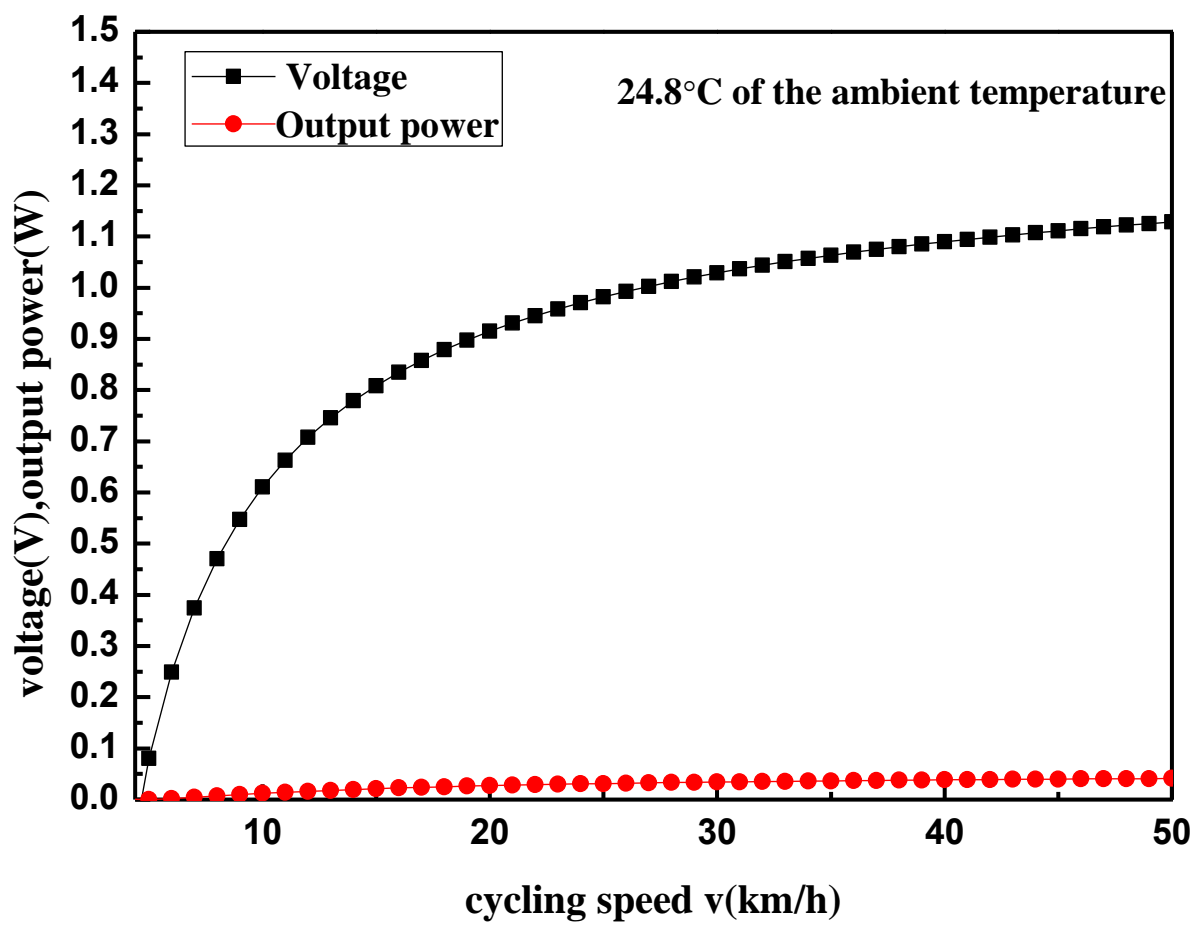

Fig. 11. Voltage and output power function of cycling speed at the highest average temperature of the year temperature of $24.8^{\circ} \mathrm{C}$. 


\section{Tables}

Table 1 properties used for simulation.

\begin{tabular}{ll}
\hline \hline Parameter & Numerical \\
\hline
\end{tabular}

\section{Environment}

The contact thermal resistance of the head and

plates of TEG $\mathrm{R}_{\text {contact } 1}$

The thermal contact resistance between TEG and

aluminum thermal slug $\mathrm{R}_{\text {contact } 2}$

The internal thermal resistance of the TEG $R_{\text {teg }} \quad 3.80 \Omega$

\section{TEG}

Numbers of $\mathrm{P}$ or $\mathrm{N}$ junction $n$

Cross-section area of one P or N junction $A_{\text {teg }} \quad 1 \times 10^{-8} \mathrm{~m}^{2}$

Seebeck coefficient $\alpha_{\text {teg }} \quad 1.35 \times 10^{-4} \quad V / K$

Electrical resistivity of one $\mathrm{P}$ or N junction $r_{\text {teg }} \quad 3.35 \times 10^{-8} \Omega \cdot m$

Height of TEG $l_{\text {teg }} \quad 3.4 \times 10^{-3} \mathrm{~m}$

\section{Heat sink}

Height of the heat sink $\mathrm{H}$

$1 \times 10^{-2} \quad m$

Length of the heat sink $\mathrm{L}$

$5 \times 10^{-2} \quad m$

Cross section area of the heat sink $S_{1}$

$1.2 \times 10^{-4} \mathrm{~m}^{2}$

Total area of the fins $S_{2}$

$1.46 \times 10^{-2} \mathrm{~m}^{2}$ 
Table 2 Thermal properties of air at $300 \mathrm{k}$, atmospheric conditions

\begin{tabular}{ll}
\hline \hline Parameter & Numerical \\
\hline$\rho \quad k g / m^{3}$ & $\mathbf{1 . 1 6 1 4}$ \\
$C_{p} \quad k J /(k g \cdot k)$ & $\mathbf{1 . 0 0 7}$ \\
$\mu \times 10^{7} \quad N \cdot s / m^{2}$ & $\mathbf{1 8 4 . 6}$ \\
$v \times 10^{6} \quad m^{2} / s$ & $\mathbf{1 5 . 8 9}$ \\
$k \times 10^{3} \quad W /(m \cdot k)$ & $\mathbf{2 6 . 3}$ \\
$\alpha \times 10^{6} \quad m^{2} / s$ & $\mathbf{2 2 . 5}$ \\
$\operatorname{Pr}$ &
\end{tabular}

Table 3 The uncertainty of the equipment

\begin{tabular}{ll}
\hline Test equipment & Uncertainly \\
\hline Voltmeter & $\pm 0.5 \%$ \\
Ammeter & $\pm 0.8 \%$ \\
Thermocouple & $0.2-0.5 \mathrm{~K}$ \\
\hline
\end{tabular}

Table 4 Basic meteorological data in Hefei

\begin{tabular}{lcccccccccccc}
\hline \hline & Jan & Feb & Mar & Apr & May & Jun & Jul & Aug & Sep & Oct & Nov & Dec \\
\hline $\begin{array}{l}\text { Average } \\
\text { Temperatur }\end{array}$ & 2.6 & 4.5 & 9.1 & 15.9 & 21.3 & 24.9 & 28 & 27.6 & 22.9 & 17.2 & 10.7 & 5 \\
e $\left({ }^{\circ} \mathrm{C}\right)$ & & & & & & & & & & & & \\
$\begin{array}{l}\text { Average } \\
\text { maximum }\end{array}$ & 6.7 & 8.8 & 18.4 & 20.7 & 25.9 & 28.9 & 31.9 & 31.9 & 27.8 & 22.1 & 15.6 & 9.7 \\
$\begin{array}{l}\text { temperature } \\
\left({ }^{\circ} \mathrm{C}\right)\end{array}$ & & & & & & & & & & & &
\end{tabular}




\begin{tabular}{|c|c|c|c|c|c|c|c|c|c|c|c|c|}
\hline $\begin{array}{l}\text { Extreme } \\
\text { maximum } \\
\text { temperature } \\
\left({ }^{\circ} \mathrm{C}\right)\end{array}$ & 20.2 & 26.4 & 29.8 & 32.7 & 35.7 & 37.8 & 39.1 & 38.9 & 38.6 & 34.3 & 29.3 & 22.5 \\
\hline $\begin{array}{l}\text { Average } \\
\text { minimum } \\
\text { temperature } \\
\left({ }^{\circ} \mathrm{C}\right)\end{array}$ & -0.6 & 1.2 & 5.5 & 11.8 & 17.1 & 21.4 & 24.8 & 24.8 & 19.8 & 13.3 & 6.7 & 1.8 \\
\hline $\begin{array}{l}\text { Extreme } \\
\text { Minimum } \\
\text { temperature } \\
\left({ }^{\circ} \mathrm{C}\right)\end{array}$ & -12 & -9.9 & -3.2 & 0.4 & 8.5 & 12.2 & 18 & 17 & 10.8 & 1.8 & -5.1 & -13 \\
\hline $\begin{array}{l}\text { Average } \\
\text { wind } \\
\text { speed }(\mathrm{m} / \mathrm{s})\end{array}$ & 2.7 & 2.8 & 3.1 & 3.2 & 3 & 2.9 & 3 & 2.8 & 2.5 & 2.5 & 2.7 & 2.6 \\
\hline
\end{tabular}

